Critique de Praxis 



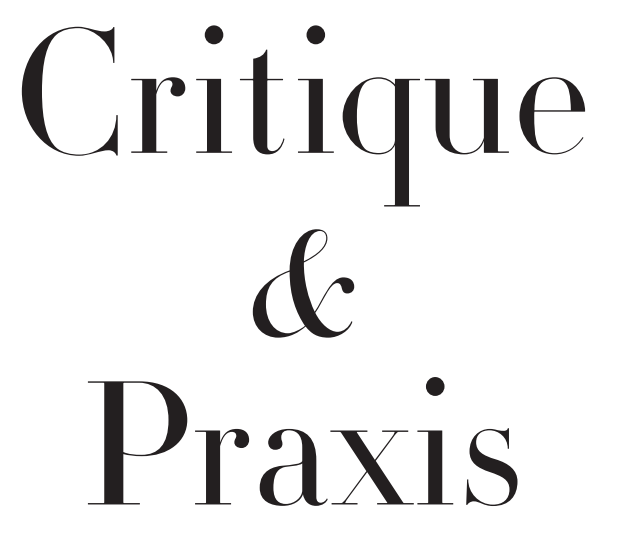

\section{A Critical Philosophy of Illusions, Values, and Action}

\section{Bernard E. Harcourt}

Columbia University Press

New York 


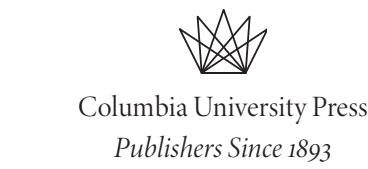

New York Chichester, West Sussex

cup.columbia.edu

Copyright (C) 2020 Bernard E. Harcourt

All rights reserved

Library of Congress Cataloging-in-Publication Data

Names: Harcourt, Bernard E., 1963- author.

Title: Critique and praxis / Bernard E. Harcourt.

Description: New York : Columbia University Press, [2020] |

Includes bibliographical references and index.

Identifiers: LCCN 2019049171 (print) | ISBN 9780231195720 (hbk) |

ISBN 9780231551458 (ebk)

Subjects: LCSH: Critical theory. | Political science-Philosophy. |

Political participation. | Social action.

Classification: LCC HM48o.H37 2020 (print) | LCC HM48o (ebook) |

DDC $142-\mathrm{dc} 23$

LC record available at https://lccn.loc.gov/2019049171

LC ebook record available at https://lccn.loc.gov/2019049172

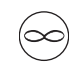

Columbia University Press books are printed on permanent and durable acid-free paper.

Printed in the United States of America

Cover design: Lisa Hamm 